\section{Renal damage during treatment with antirheumatic drugs}

Beta-N-acetyl glucosaminidase (NAG) is a lyosomal enzyme found in high concentrations in the epithelial cells of renal tubules. It is excreted in the urine of normal people, but much larger quantities are excreted by patients with renal disease, ${ }^{1}$ those taking nephrotoxic drugs, ${ }^{2}$ and those starting treatment with aspirin. ${ }^{3}$ Measuring NAG excretion may be a convenient way of assessing early damage to renal tubules: the output rises sharply within a few days of the onset of the insult. The present study used NAG excretion to explore the possibility that non-steroidal anti-inflammatory drugs other than aspirin might also damage renal tubules. Enzyme excretion was also monitored in patients with rheumatoid arthritis receiving long-term treatment with D-penicillamine or levamisole.

\section{Methods and results}

Normal subjects, or patients with osteoarthritis but no renal disease or hypertension, were included in the first study. Aliquots of urine were obtained before giving the drugs, and again at intervals during the course of treatment. The drugs studied were aspirin, diflunisal, indomethacin, ibuprofen, naproxen, and azopropazone in their usual therapeutic doses. Aspirin and diflunisal were tested in both high- and low-dose regimens. In a second study, patients with rheumatoid arthritis starting treatment with D-penicillamine or levamisole were observed for intervals up to six months. Measurements of disease activity were observed over the same period. Specimens were stored at $4^{\circ} \mathrm{C}$ before analysis by the fluorimetric method of Tucker et al. ${ }^{4}$

The results are shown in the table. No significant increase in NAG excretion was seen with the lower dose of aspirin or diflunisal, but concentrations were appreciably increased with higher dosage, this effect being sustained at six weeks. In tests on patients taking the other non-steroidal anti-inflammatory drugs, no increase in urinary excretion of NAG was observed. When patients with rheumatoid arthritis were treated with either D-penicillamine or levamisole a significant fall in NAG excretion was observed by the 12th week, and maintained at 26 weeks. This decrease seemed to correlate with improvement in clinical estimates of disease activity. No increase in NAG excretion was observed in eight other patients receiving D-penicillamine who developed proteinuria.

\section{Comment}

Aspirin has a dramatic acute effect on the excretion of renal tubular cells and enzymes, but its long-term effects on the kidney are small, and probably of little clinical importance. ${ }^{4}$ Nevertheless, it has been suggested that other, newer analgesic anti-inflammatory drugs might also be nephrotoxic, highlighting the need for a sensitive test of early renal changes. NAG excretion is a useful screening test for renal tubular damage. In the present study only aspirin and diflunisal increased NAG excretion, and this effect was dose dependent. It therefore seems unlikely that the other agents will cause long-term damage to renal tubular function.

NAG excretion fell during long-term treatment of rheumatoid arthritis with D-penicillamine and levamisole. In view of the known relation between NAG excretion and disease activity, ${ }^{5}$ this is probably due to effective treatment of the disease. The fact that there was no rise in NAG excretion in patients who developed proteinuria while taking penicillamine is presumably because this complication results from damage to the glomerular basement membrane, and not renal tubular cells.

In conclusion, NAG excretion is a useful means of monitoring drugs for adverse effects on the renal tubules, but does not detect early glomerular damage. None of the newer analgesic antiinflammatory drugs, not related to aspirin, had a significant effect on NAG excretion.

We acknowledge the excellent work of the late Susan Tucker, who carried out the enzyme estimations for this study.

${ }^{1}$ Ellis, B G, et al, Clinica Chimica Acta, 1975, 64, 195.

2 Wellwood, J M, et al, British Medical fournal, 1975, 3, 278.

${ }^{3}$ Burry, H C, et al, British Medical fournal, 1976, 1, 613.

4 Tucker, S M, et al, Clinica Chimica Acta, 1975, 62, 333.

5 Dieppe, P A, et al, British Medical fournal, 1976, 1, 611.

(Accepted 14 June 1978)

University Department of Medicine, Bristol Royal Infirmary, Bristol BS2 8HW

P A DIEPPE, BSC, MRCP, consultant rheumatologist

Department of Rheumatology, St Bartholomew's Hospital, London EC1A 7BE

D V DOYLE, MRCPI, senior registrar

Hutt Hospital, Wellington, New Zealand

H C BURRY, FRCP, FRACP, consultant rheumatologist

\section{Avascular necrosis of bone after renal transplantation: role of parathyroid hormone and vitamin $D$}

Avascular necrosis of bone is a common complication after renal transplantation but its aetiology is obscure. We have investigated whether there is any relation between this condition and parathyroid activity, and also assessed various clinical indices and the vitamin D status in 63 transplanted patients.

\section{Patients and results}

A total of 38 men and 25 women (age range 17-49) with functioning renal grafts were studied. They had been transplanted two months to 11 years previously and the kidneys used were predominantly from cadaveric donors. The diagnosis of avascular necrosis was based on radiological findings.

Some 22 patients $(34 \cdot 9 \%$ ) had radiological evidence of avascular necrosis of bone, the prevalence being higher in men (16/38) than in women $(6 / 25)$. The duration of renal failure and length of dialysis treatment before transplantation were similar in patients with and without avascular necrosis. Graft rejection episodes, which required increase of the dose of steroids, occurred in all but two patients. The incidence was 2.5 . per patient for those who had avascular necrosis and 2.09 for those who did not (not significant). Each rejection episode was treated with 3-6 $\mathrm{g}$ of prednisolone over 30 days. Maintenance dose was $15 \mathrm{mg}$ daily in all patients. A summary of the biochemical findings is shown in the table. No difference could be found between patients with and without avascular necrosis for any of the values studied. The mean concentration of 25-hydroxy vitamin D (25-OHD) was higher in patients with the complication but still within the normal range. Hypercalcaemia was present in three of the 22 patients with avascular necrosis $(13.6 \%)$ and in three of the remaining 41 patients (7.3\%) (not significant).

$N A G$ excretion before and during treatment with various antirheumatic drugs

\begin{tabular}{|c|c|c|c|c|c|c|c|c|c|c|}
\hline Drug & Aspirin & Aspirin & Diflunisal & Diflunisal & Ibuprofen & Indomethacin & Naproxen & Azopropazone & Levamisole & $\stackrel{\mathrm{D}-}{\text { Penicillamine }}$ \\
\hline $\begin{array}{l}\text { Dose per day } \\
\text { No of subjects } \\
\text { Duration of study (weeks) } \\
\text { Diagnosis } \\
\text { NAG concentration } \\
\text { before treatment } \\
\text { nmol/h/mg creatinine }\end{array}$ & $\begin{array}{c}>1<2 \mathrm{~g} \\
5 \\
2 \\
\text { OA } \\
33 \cdot 4\end{array}$ & $\begin{array}{c}>2<4 \mathrm{~g} \\
12 \\
6 \\
\text { OA } \\
41 \cdot 25\end{array}$ & $\begin{array}{c}500-750 \mathrm{mg} \\
7 \\
2 \\
\text { OA } \\
45 \cdot 7\end{array}$ & \begin{tabular}{|c}
$750-1500 \mathrm{mg}$ \\
12 \\
6 \\
OA \\
82.08
\end{tabular} & $\begin{array}{c}1600 \mathrm{mg} \\
6 \\
3 \\
\text { OA } \\
95 \cdot 83\end{array}$ & $\begin{array}{c}150 \mathrm{mg} \\
6 \\
3 \\
\text { OA } \\
82 \cdot 5\end{array}$ & $\begin{array}{c}500 \mathrm{mg} \\
14 \\
2 \\
\mathrm{OA} \\
115 \cdot 62\end{array}$ & $\begin{array}{c}1200 \mathrm{mg} \\
10 \\
2 \\
\text { Normal } \\
86 \cdot 32\end{array}$ & $\begin{array}{c}150 \mathrm{mg} \\
10 \\
26 \\
\mathrm{RA} \\
214 \cdot 0\end{array}$ & $\begin{array}{c}500-1000 \mathrm{mg} \\
8 \\
26 \\
\mathrm{RA} \\
123 \cdot 2\end{array}$ \\
\hline $\begin{array}{l}\text { NAG concentration } \\
\mathrm{nmol} / \mathrm{h} / \mathrm{mg} \text { creatinine }\end{array}$ & $26 \cdot 8$ & $107 \cdot 8$ & $35 \cdot 0$ & $142 \cdot 9$ & $84 \cdot 26$ & $84 \cdot 16$ & $110 \cdot 15$ & $78 \cdot 80$ & $141 \cdot 3$ & $80 \cdot 6$ \\
\hline Significance of change $(P)$ & NS & $<0.05$ & NS & $<0.05$ & NS & NS & NS & NS & $<0.05$ & $<0.02$ \\
\hline
\end{tabular}

OA = Osteoarthrosis. $\quad \mathrm{RA}=$ Rheumatoid arthritis. $\quad \mathrm{NS}=$ Not significant. 
Biochemical data in 63 transplanted patients. Values are means $\pm S E$ of mean

\begin{tabular}{|c|c|c|c|c|}
\hline Concentrations & $\begin{array}{c}\text { All } \\
\text { patients } \\
(n=63)\end{array}$ & $\begin{array}{c}\text { With } \\
\text { avascular } \\
\text { necrosis } \\
(\mathbf{n}=22)\end{array}$ & $\begin{array}{l}\text { Without } \\
\text { avascular } \\
\text { necrosis } \\
(n=41)\end{array}$ & $\begin{array}{l}\text { Normal } \\
\text { values }\end{array}$ \\
\hline $\begin{array}{l}\text { Serum calcium }(\mathrm{mmol} / \mathrm{l}) \\
\text { Serum phosphate }(\mathrm{mmol} / \mathrm{l})\end{array} \ldots$ & $\begin{array}{l}2 \cdot 51 \pm 0 \cdot 01 \\
0.98 \pm 0.04 \\
46.9 \pm 2 \cdot 4 \\
0.45 \pm 0.04 \\
25 \cdot 4 \pm 1 \cdot 8 \\
2 \cdot 17 \pm 0 \cdot 19 \\
13.5 \pm 0.9 \\
79.4 \pm 4 \cdot 8\end{array}$ & $\begin{array}{l}2 \cdot 48 \pm 0 \cdot 05 \\
1.01 \pm 0.02 \\
50 \cdot 3 \pm 5 \cdot 1 \\
0 \cdot 48 \pm 0.07 \\
30 \cdot 9 \pm 3 \cdot 6 \\
2 \cdot 11 \pm 0.3 \\
12.9 \pm 1 \cdot 10 \\
78 \cdot 6 \pm 7 \cdot 9\end{array}$ & $\mid \begin{array}{l}2 \cdot 51 \pm 0 \cdot 02 \\
0 \cdot 96 \pm 0 \cdot 04 \\
44 \cdot 2 \pm 2 \cdot 5 \\
0 \cdot 40 \pm 0 \cdot 04 \\
22 \cdot 4 \pm 1 \cdot 8 * \\
2 \cdot 20 \pm 0 \cdot 25 \\
13 \cdot 9 \pm 1 \cdot 30 \\
80 \cdot 5 \pm 6 \cdot 2\end{array}$ & $\begin{array}{c}2 \cdot 25-2 \cdot 62 \\
0 \cdot 80-1 \cdot 40 \\
20-90 \\
<0 \cdot 156-1 \cdot 0 \\
3-40\end{array}$ \\
\hline
\end{tabular}

$* \mathbf{P}<0.05$.

Conversion: SI to traditional units-Serum calcium: $1 \mathrm{mmol} / 1 \approx 4 \mathrm{mg} / 100 \mathrm{ml}$. Serum phosphate: $1 \mathrm{mmol} / 1 \approx 3.2 \mathrm{mg} / 100 \mathrm{ml}$. Urinary calcium: $1 \mathrm{mmol} / 24 \mathrm{~h} \approx$
$40 \mathrm{mg} / 100 \mathrm{ml}$. Urinary phosphate: $1 \mathrm{mmol} / 24 \mathrm{~h} \approx 0.031 \mathrm{~g} / 24 \mathrm{~h}$.

Hypercalcaemia was shown in a single sample from each patient and other factors which might have been responsible for it-for example, immobilization-were excluded. In the six hypercalcaemic patients, who had all received their grafts between three and eight years before this study, the serum parathyroid hormone concentration was within the normal range but perhaps not suppressed to the degree that might have been expected for the high concentrations of serum calcium. Circulating parathyroid hormone concentration was also normal in all but one of the remaining patients. No patient had a serum 25-OHD concentration below the normal range.

\section{Comment}

In this study the prevalence of radiological avascular necrosis of bone was as high as $35 \%$. This is one of the highest reported but in most of our patients it would not have been recognised if radiological screening had not been done. Only four patients required hip replacement. Steroid treatment did not seem to have been responsible, as the incidence of graft rejection episodes was similar in patients with and without avascular necrosis and the maintenance steroid dosage was the same in both groups.

Hyperparathyroidism is a common complication of chronic renal failure and usually subsides after renal transplantation. In some successfully transplanted patients with normal renal function, however, parathyroid overactivity has been reported to persist for years ${ }^{12}$ and this has been implicated in the pathogenesis of avascular necrosis of bone. ${ }^{3}$

All but one of our patients had normal circulating parathyroid hormone concentrations. No difference in parathyroid activity could be shown between patients who had avascular necrosis and those who did not. Moreover, no differences in serum or urinary phosphate concentrations were found.

Measurements of serum 25-OHD concentrations can be used as an index of the vitamin $D$ status in man. As we found, transplanted patients had normal 25-OHD concentrations and vitamin $\mathrm{D}$ cannot be implicated in the pathogenesis of avascular necrosis of bone. We therefore conclude that the avascular necrosis of bone in our transplanted patients was due neither to parathyroid overactivity nor to vitamin $\mathrm{D}$ deficiency and that other factors must be sought.

We thank the nurses and the secretary of the Fleming Ward of St Mary's Hospital for their help and co-operation. J L H O'Riordan is grateful to the National Kidney Research Fund for financial support.

Correspondence to $\mathrm{BH}$.

1 David, D S, et al, New England fournal of Medicine, 1973, 289, 398.

2 Kleerkoper, M, et al, British Medical fournal, 1975, 3, 680.

3 Chatterjee, S N, et al, Nephron, 1976, 17, 1.

(Accepted 23 fune 1978)

Renal Unit, St Mary's Hospital, London W2

C M PAGE, MRCP, registrar

B HULME, MD, FRCP, consultant physician

Department of Medicine, The Middlesex Hospital, London W1

S E PAPAPOULOS, MD, Astor Research Fellow

J L H O'RIORDAN, DM, FRCP, senior lecturer and honorary consultant physician

\section{Solitary diverticulum of transverse colon masquerading as polyp}

Solitary diverticulum of the transverse colon is a rare developmental abnormality, which in the case we report gave rise to the appearances on barium enema investigation of a solitary polyp. This misleading radiological finding resulted in difficulty in locating the diverticulum, which was completely intramesenteric and therefore not visible except at colotomy. We present our experience as a caution to others.

\section{Case report}

A 52-year-old woman presented with a two-week history of passing bright red blood on defaecation. She had had no change in her bowel habit or loss of weight. Sigmoidoscopy showed no abnormality and proctoscopy only minor haemorrhoids. A barium enema showed a lobulated lesion in the region of the hepatic flexure (fig) judged to be a polyp. Laparotomy was performed but no polyp palpated at the appropriate site. Colotomy and thorough inspection of the colonic lumen also failed to show a polyp. It was concluded that faeces might have accounted for the "polyp" and the laparotomy ended. After convalescence another barium enema was performed and this showed the same abnormality to be present. Colonoscopy was

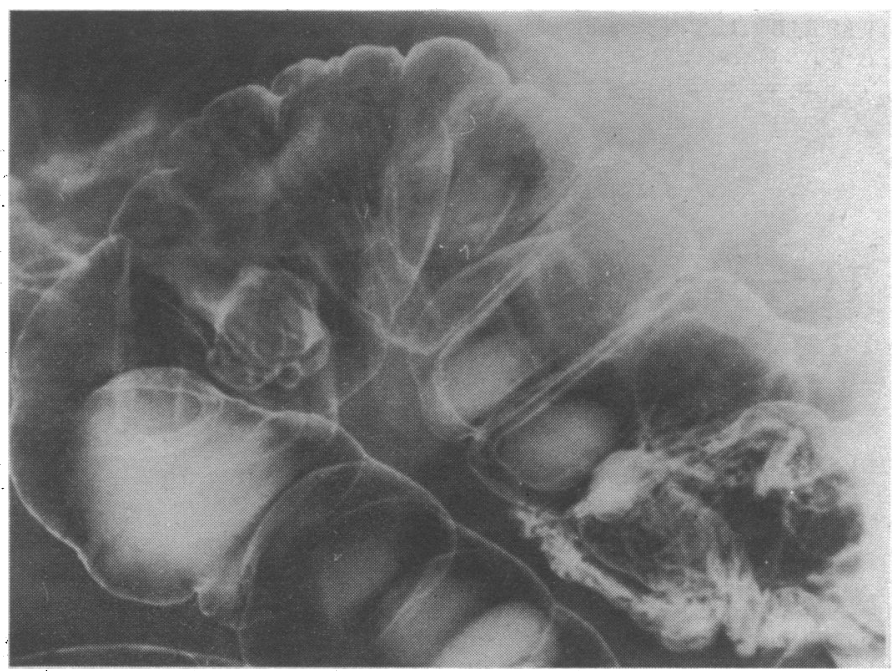

Solitary diverticulum of transverse colon, near hepatic flexure.

undertaken, but, mainly because of a long sigmoid colon, the hepatic flexure could not be visualised.

In view of the possibility of missed malignancy a second laparotomy was undertaken. Again no polyp was palpable and again a colotomy was performed. Thorough exploration showed the neck of a congenital diverticulum of $1-\mathrm{cm}$ diameter in the region of the hepatic flexure. This was not visualised from the bowel exterior as it was completely intramesenteric, being three $\mathrm{cm}$ long. A localised resection of the hepatic flexure was performed and the patient made an uneventful recovery. Histological examination showed a simple diverticulum with no appreciable abnormality in sections of the mucosa. An adjacent lymph node was normal.

\section{Comment}

A review of British and American reports over the past ten years has shown none of a solitary diverticulum of the transverse colon presenting in this fashion. Solitary or congenital diverticula are rare developmental abnormalities found in the large bowel, and may be associated with vertebral defects. ${ }^{1}$ They are found in the rectum and occasionally in the colon and commonly have a more or less complete covering of all bowel coats. The incidence of solitary diverticulum of the transverse colon is undetermined. Necropsy studies have put the incidence of solitary diverticulum of the caecum at between 2.5 and $5.0 \%$ of the general population. ${ }^{2}$ These were all found to be thinwalled "false" diverticula. The same study found acquired diverticular disease in $43 \%$ of cadavers, but failed to find any case of congenital diverticulum in the 200 colons studied.

Chugntal and Ackerman described six patients with congenital solitary diverticula of the transverse colon all of which presented with 